\title{
Large carnivores and low diversity of optimal prey: a comparison of the diets of snow leopards Panthera uncia and wolves Canis lupus in Sarychat-Ertash Reserve in Kyrgyzstan
}

\author{
Kubanychbek Jumabay-Uulu, Per Wegge, Charudutt Mishra \\ and KOUSTUBH SHARMA
}

\begin{abstract}
In the cold and arid mountains of Central Asia, where the diversity and abundance of wild ungulates are generally low, resource partitioning among coexisting carnivores is probably less distinct than in prey-rich areas. Thus, similar-sized carnivores are likely to compete for food. We compared the summer diets of snow leopards Panthera uncia and wolves Canis lupus in Sarychat-Ertash Reserve in the Tien-Shan mountains of Kyrgyzstan, based on analysis of genetically confirmed scats. Abundances of the principal prey species, argali Ovis ammon and Siberian ibex Capra sibirica, were estimated from field surveys. The diets consisted of few species, with high interspecific overlap (Pianka's index $=0.91$ ). Argali was the predominant prey, with $>50 \%$ frequency of occurrence in both snow leopard and wolf scats. This was followed by Siberian ibex and marmots Marmota baibacina. Being largely unavailable, remains of livestock were not detected in any of the scats. In the snow leopard diet, proportions of argali and ibex were in line with the relative availabilities of these animals in the Reserve. This was in contrast to the diet of wolf, where argali occurred according to availability and ibex was significantly underrepresented. The high diet overlap indicates that the two predators might compete for food when the diversity of profitable, large prey is low. Competition may be more intense in winter, when marmots are not available. Hunting of argali and ibex outside the Reserve may be unsustainable and therefore reduce their abundances over time. This will affect both predators negatively and intensify competition for food. Reduction in ibex populations will directly affect the snow leopard, and the wolf is likely to be indirectly affected as a result of increased snow leopard predation of argali.
\end{abstract}

KubanychbeK Jumabay-UUlU Snow Leopard Foundation in Kyrgyzstan, Bishkek, Kyrgyzstan

PER WEgGE (Corresponding author) Department of Ecology and Natural Resource Management, Norwegian University of Life Sciences, NO-1432 Ås, Norway. E-mail per.wegge@umb.no

Charudutt Mishra and Koustubh Sharma Snow Leopard Trust and Nature Conservation Foundation, Mysore, India

Received 11 October 2012. Revision requested 7 January 2013.

Accepted 20 February 2013. First published online 26 July 2013.
Keywords Canis lupus, Central Asia, food habits, intraguild competition, Panthera uncia, scat analysis

\section{Introduction}

$\mathrm{V}$ arious forms of competition during evolutionary time imply that species within a guild are likely to coexist through resource partitioning (Begon et al., 1996). In preyrich areas predators may coexist by exploiting different prey species (Karanth \& Sunquist, 2000; Odden et al., 2010), whereas in areas of limited prey predators may compete with each other (Koshkarev, 1989; Harihar et al., 2011). In the mountains of Central Asia the diversity and abundance of wild ungulates are generally low. Consequently, sympatric large carnivores such as the snow leopard Panthera uncia and the wolf Canis lupus may be expected to have a high potential for competitive interactions. However, diet overlap and competition may be low if the two species use different habitats and hunting tactics. For example, the stalking snow leopard largely uses steep, broken terrain (Jackson \& Hunter, 1996) and the cursorial pack-hunting wolf uses a greater diversity of topography, including open valleys and rolling hills (Viripaev \& Vorobiev, 1983), leading to some level of separation of habitat, and possibly diet.

The snow leopard is categorized as Endangered on the IUCN Red List and is listed in Appendix I of CITES. Habitat degradation, poaching, retaliatory killing in response to livestock depredation and prey depletion are the key factors leading to population declines (Nowell \& Jackson, 1996; Mishra, 1997; McCarthy, 2000; Lovari et al., 2009). In Kyrgyzstan, numbers declined from an estimated 600-700 individuals in the late 1980s (Koshkarev, 1989) to $150-200$ individuals by 2000 (Koshkarev \& Viripaev, 2000), putting the species at high risk of extinction in the country.

In contrast, wolves are common in Central Asia and are considered a pest animal in many countries, with governments offering financial incentives for killing them (Lescureux, 2006; Mijiddorj, 2011). According to a recent report of the Kyrgyz Hunting Agency (2010) 157 wolves were killed in 2010 and their population was estimated to be $>3,500$. 
Argali Ovis ammon and Siberian ibex Capra sibirica are the main prey of snow leopards and wolves in Kyrgyzstan (Viripaev \& Vorobiev, 1983). In most of Central Asia the decline in populations of mountain ungulates has been attributed to poorly managed hunting programmes, poaching and overharvesting (Weinberg et al., 1997). Marmots Marmota baibacina, which constitute a smaller, seasonal prey, have also faced considerable threats. Between 1950 and 1960 an estimated one million marmots were poisoned during an eradication programme to prevent the spread of plague (BSAP, 1996). Reoccurrence of plague may trigger a repeat of large-scale eradication programmes. What are the likely impacts of prey declines on snow leopards and wolves and on their niche relationships? Will populations of these carnivores decline in the same way as their prey populations, or will they be affected differently? To answer these questions and to understand intraguild interactions, we examined the diets of snow leopards and wolves during summer, when argali, Siberian ibex and marmots are available. We conducted our study in the Sarychat-Ertash Reserve in Kyrgyzstan. We predicted that the different hunting strategies of snow leopards and wolves would result in divergence in their diets, with snow leopards preying mainly on ibex and wolves on argali. In the case of marmots, their abundance is greater in foothills and valleys that are used by wolves, but in many areas they are reported to constitute an important seasonal prey for the snow leopard (Schaller et al., 1988). We therefore predicted that both carnivores would prey on marmots.

\section{Study area}

The $1,341 \mathrm{~km}^{2}$ Sarychat-Ertash Reserve is at an altitude of 2,000-5,500 $\mathrm{m}$ in the upper reaches of the Uch-Kol River basin in the Tien-Shan mountain range (Fig. 1). The flat river bottom, with steep slopes on both sides, is up to nearly $1 \mathrm{~km}$ wide. The climate is cold and continental, with mean monthly temperatures in June and January of +4.2 and $-21.5^{\circ} \mathrm{C}$, respectively. Annual precipitation is $295 \mathrm{~mm}$, with nearly half falling in June-August (SER, 2007).

Vegetation consists of three main types: arid grasslands, wet meadows, and tundra cushion plants (Zlotin, 1997). Snow leopard, wolf and red fox Vulpes vulpes are the most common carnivores; brown bear Ursus arctos, lynx Lynx lynx, manul Felis manul and stone marten Martes foina are also present. In addition to ibex and argali, potential prey species include marmot, hare Lepus tolai, pika Ochotona roylei, and birds such as snowcock Tetraogallus himalayensis and chukar partridge Alectoris chukar. There are reports of four species of mustelids and four vole species in the area (SER, 2007).

Before the Reserve was established in 1995 the area had been under pressure from human activities. Three
Soviet collective farms used the area for livestock grazing year-round, keeping c. 4,800 domestic sheep Ovis aries there during winter. Heavy livestock grazing, illegal hunting, road building, geological exploration and other activities took place. By 2012 only a small part of the Reserve's buffer zone was used for seasonal livestock grazing. There are two small villages near the Reserve. The nearest is Ak-Shiyrak, which has c. 25 households ( 70 people) and is $7 \mathrm{~km}$ south of the Reserve. Fourteen villagers from Ak-Shiyrak work as rangers in the Reserve, and livestock herding (sheep and horses) is the main source of income for the village.

The Reserve was part of the area covered by the marmot eradication programme in the 1950s, after epidemiologists discovered plague in the Central Tien-Shan (BSAP, 1996).

\section{Methods}

\section{Scat collection}

In 2009 we collected scats along $14 \quad 0.6-1.5 \mathrm{~km}$ transects spaced $3-5 \mathrm{~km}$ apart. The transects were along ridges, tributary streams (nullah) and the bases of cliffs, extending upwards from the flat valley bottom on both sides of the main river. We took samples four times between June and October, with at least 20 days between trips to allow fresh scats to be deposited. Only a part of the scat was collected. Uncollected material was left in its original location, and to avoid re-sampling the same scat in subsequent trips it was marked with red nail polish. We also collected scats opportunistically while travelling to and between transects, sampling proportionally more of the flat and grassy slopes closer to the main river. Small pieces of the fresh samples were collected in plastic tubes with silica gel for DNA analysis, and larger pieces were collected in paper envelopes and air-dried for microhistological diet analysis.

\section{Genetic screening of scats}

Recent studies have demonstrated that carnivore scats collected in the field are often misclassified (Janecka et al., 2008; Anwar et al., 2011; Shehzad et al., 2012; Wegge et al., 2012). When using scats for dietary analysis it is therefore necessary to control for species identity. Our scat samples were genetically screened at the American Museum of Natural History. Following extraction of genomic DNA, species identification was based on four mitochondrial DNA fragments (CytB, 12S, 16S and ATP6). Each identified target species was reconfirmed by genotyping three times. For further information on the laboratory procedure used at the Museum see Shehzad et al. (2012). 


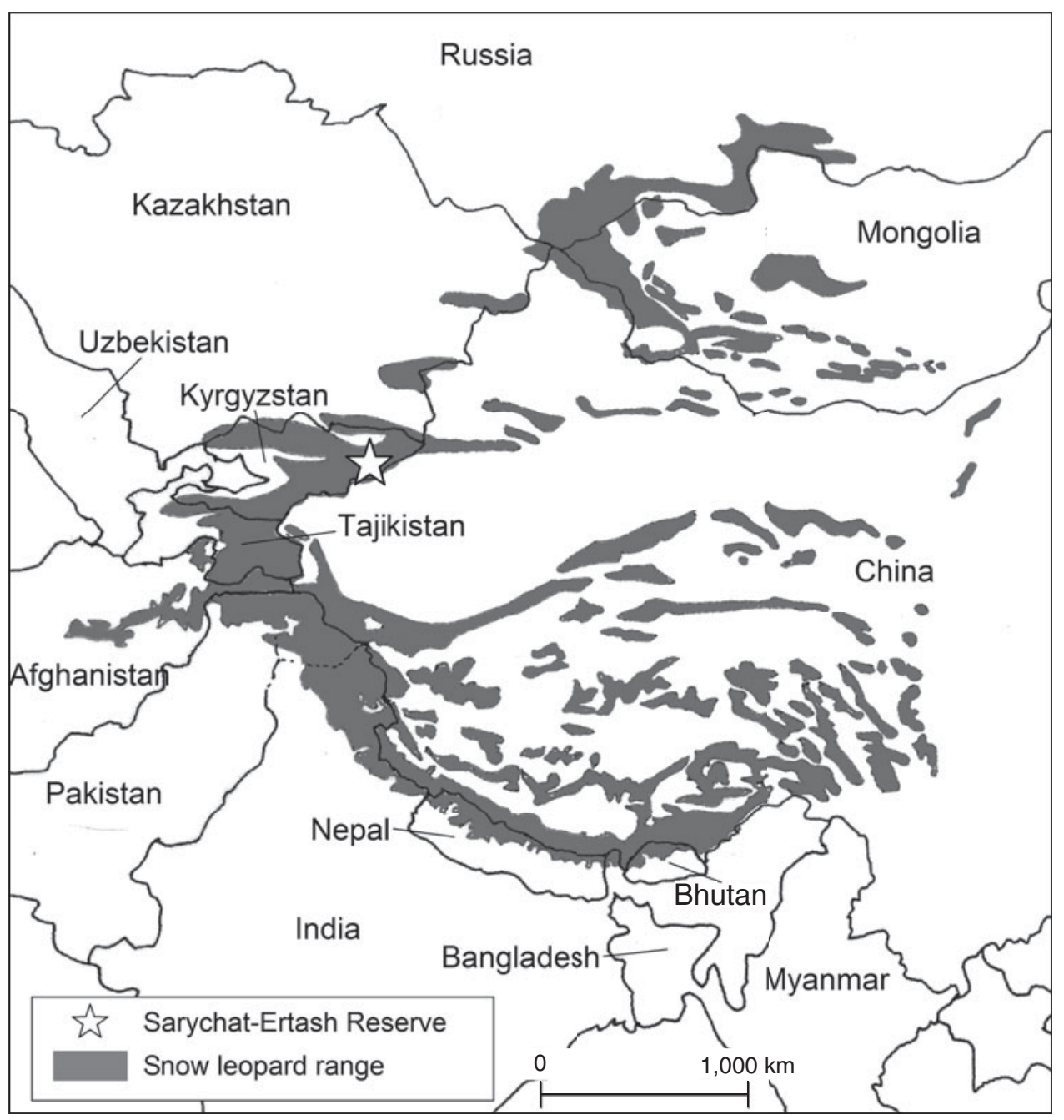

FIG. 1 Snow leopard Panthera uncia range, adapted from Fox (1994), and the location of the study area, Sarychat-Ertash Reserve, in Kyrgyzstan.

\section{Reference key and laboratory analysis}

We collected reference hair samples from the remains of ungulate species found in the study area and from specimens maintained at the Kyrgyz Academy of Sciences. Different types of livestock hair were taken from the villages near the study area. Hair types were selected from different body parts and fixed in envelopes marked with the species name. A photographic key of all potential prey species was prepared by taking pictures of hair structures with a microscopic camera at $40 \times$ magnification. As the hair scale patterns of ibex and argali are similar, we identified the species from cross-sectional cuttings of primary guard hairs, which were photographed at $60 \times$ magnification (Oli, 1993). All scat samples were first oven-dried for 24 hours at $90{ }^{\circ} \mathrm{C}$ and then washed and sieved under running water. To extract hairs of ungulates we used a mesh size of $0.8 \mathrm{~mm}$ and for small mammal hair a mesh of $0.5 \mathrm{~mm}$. Matter such as bones, stones and plant material was manually separated, dried and stored in annotated plastic bags.
To identify prey species we used a modified version of the point frame method (Stewart, 1967; Ciucci et al., 2004): instead of using drop pins to select the prey items we used tweezers to select the prey items at each intersection $(\mathrm{n}=50)$ in a gridded tray (Wegge et al., 2012) and examined these under a dissecting scope, or a high-power microscope if necessary for reliable identification. The hair of marmot and hare was easily identified by colour, size, shape, length and scale patterns. Small rodents could not be identified to species and were therefore classified simply as rodents. Besides using the photographic key, important features for use in hair identification were taken from Brunner \& Coman (1974) and Oli (1993).

\section{Abundances of main wild prey}

Abundances of ungulate prey were estimated from total counts in 2007 (ibex) and 2009 (argali). The argali census was conducted shortly before the rut in late autumn, when animals aggregate at lower elevations. During a 10-day period a team of five observers, using binoculars and 
spotting scopes, traversed the central part of the Reserve, including all side-drainages, where scats were also sampled, and counted all animals seen. They were classified according to sex and age classes whenever possible. Landscape features, direction of movement, and herd composition helped to avoid multiple counting of the same groups. The ibex census was conducted by teams of well-trained Reserve rangers using the same method in the same area during winter, because ibex is more easily observed and counted during the snowy winter season. The results were extrapolated from the census report filed at the Reserve headquarters (SER, 2007).

\section{Statistical analyses}

Because smaller prey are composed of proportionally more indigestible material than larger prey, they occur in scats at higher relative proportions per unit ingested than larger prey (Floyd et al., 1978). Based on feeding trials, correction factors have been developed to account for this. For the snow leopard we used the equation developed by Ackerman et al. (1984) for the cougar Felis concolor $(y=1.980+0.035 x)$, and for wolves we used the equation $(y=0.439+0.008 x)$ developed by Weaver (1993), where $y$ is the biomass of prey consumed $(\mathrm{kg})$ to produce a single scat, $x$ is the mean body weight of the prey species $(\mathrm{kg})$, and $x / y$ represents the total number of scats produced by consumption of a single individual of a species.

Mean weights of prey species were taken from Iyanushevich et al. (1972). The use of correction factors to calculate estimates of biomass and number of prey consumed from the amount of remains in scats is an established technique in carnivore scat analysis (Link \& Karanth, 1994; Bagchi et al., 2004; Müller, 2006; Wegge et al., 2009). To compare selection of main prey by snow leopards and wolves we generated expected frequencies from the mean density estimates of argali and ibex, with coefficients of variation assumed to be $50 \%$. We applied such large coefficients of variation to allow for errors, given that the density estimates were not robust and did not report variances. Using these mean densities and their variances we applied a parametric bootstrap procedure to generate random prey densities according to a normal distribution. For each likelihood ratio test, 500 bootstrap simulations were run to generate sets of densities, hypothesized scat frequencies and $G^{2}$ statistics. The mean P-values associated with $G^{2}$ statistics from these simulations were used to infer predator selectivity patterns. Simulations were run for all three principal prey species (argali, ibex and marmot), for both snow leopards and wolves. Details of this statistical methodology were described by Link \& Karanth (1994).

We used SCATMAN (USGS, Laurel, USA; Hines \& Link, 1994) to analyse the diets. The scat production rate was estimated as $x / y$, and the variability of this rate was

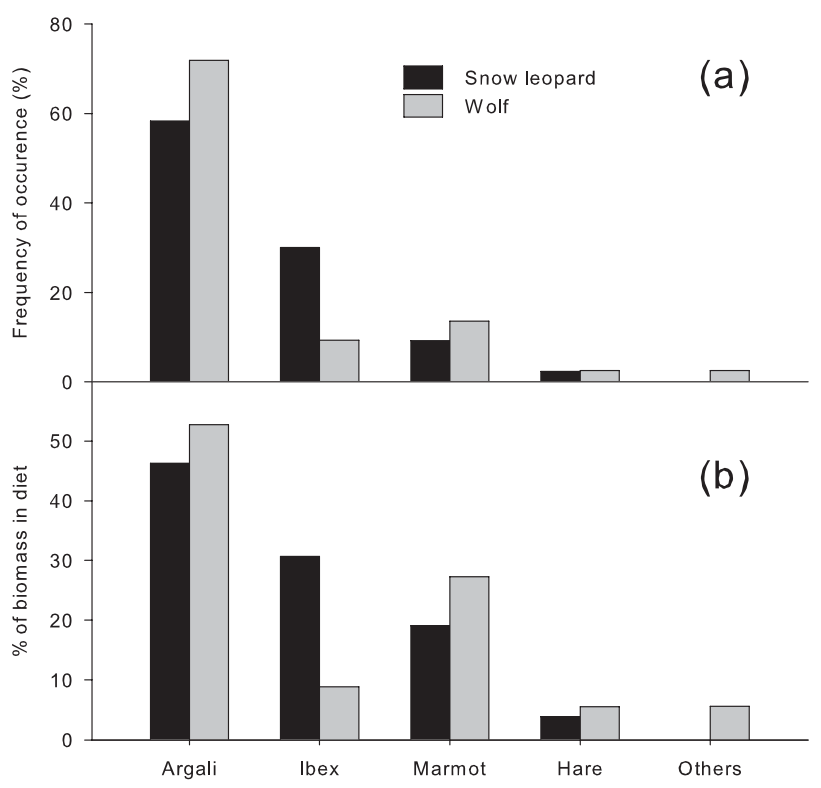

FIG. 2 Composition of summer diets of snow leopards and wolves in Sarychat-Ertash Reserve (Fig. 1) in terms of (a) frequency of occurrence and (b) biomass consumed, derived from analysis of scats.

considered to be a constant $40 \%$. This was done to incorporate the large variation between the body masses of different age/sex classes of each of the primary prey species. As the physiologies of the two predators are different, the numbers of scats they produce after consuming the same prey species of the same size will vary. This results in different proportions of scats for each predator for a given density of prey. Diet diversity was estimated using the standardized Levin's index $\left(B_{\mathrm{a}}\right.$; Colwell \& Futuyma, 1971), and diet overlap was estimated using Pianka index (Pianka, 1973).

\section{Results}

We collected 98 fresh scats in an area of c. $700 \mathrm{~km}^{2}$. Of 59 putative snow leopard scats, $39(67 \%)$ were confirmed by genetic analysis to be from snow leopard. The others were from red fox (12), stone marten (3) and unknown species (5). Of 50 putative wolf scats, $36(72 \%)$ were confirmed to be from wolf. The others were from brown bear (4) and unknown species (2), and eight were from snow leopard, raising the sample size of this species to 47 scats. Accumulation curves showed that the verified samples were sufficient for the diet analysis because the relative contribution of prey species to the diets stabilized at 30-35 scats.

The diets of the two carnivores are given in Fig. 2, showing the composition based on the frequency of occurrence of prey remains in scats and based on percentage contribution of biomass of each specific prey consumed (plant material is omitted). Argali was the most important prey in the diet of both carnivores, constituting c. $50 \%$ of the 
TABLE 1 Selection of primary prey species (argali Ovis ammon and ibex Capra sibirica) by wolf Canis lupus and snow leopard Panthera uncia in Sarychat-Ertash Reserve (Fig. 1) during summer 2009 , based on scat analysis. Significant preference or avoidance is indicated in bold font.

\begin{tabular}{lll}
\hline & Argali & Ibex \\
\hline $\begin{array}{l}\text { Estimated density }\left(\mathrm{no} . / \mathrm{km}^{2}\right) \\
\text { Wolf }\end{array}$ & 1.28 & 0.71 \\
$\begin{array}{l}\text { Observed frequency of occurrence } \\
\text { in scats }\end{array}$ & 18 & $\mathbf{3}$ \\
$\begin{array}{l}\text { Expected frequency of occurrence } \\
\text { in scats }\end{array}$ & 18.6 & $\mathbf{8 . 8}$ \\
$\chi^{2}$ & 0.04 & $\mathbf{5 . 4 1}$ \\
$\mathrm{P}$ & $\mathrm{p}>0.80$ & $\mathbf{p}<\mathbf{0 . 0 5}$ \\
$\begin{array}{l}\text { Snow leopard } \\
\begin{array}{l}\text { Observed frequency of occurrence } \\
\text { in scats }\end{array}\end{array}$ & 12 & 8 \\
$\begin{array}{l}\text { Expected frequency of occurrence } \\
\text { in scats }\end{array}$ & 12.8 & 6.0 \\
$\chi^{2}$ & 0.09 & 0.85 \\
$\mathrm{P}$ & $\mathrm{p}>0.70$ & $\mathrm{p}>0.35$ \\
\hline
\end{tabular}

diet of snow leopards and $>60 \%$ of the diet of wolves. Ibex constituted a larger percentage of the diet of snow leopards (c. $30 \%)$ than of wolves (c. 10\%), and marmots were more commonly found in the wolf scats (c. $20 \%$ of samples) than in the snow leopard scats (c. $8 \%$ of samples). Remains of the shrub myricaria Myricaria bracteata were found in $45 \%$ of the snow leopard scats. Livestock remains were not detected in any samples. Other samples consisted mainly of rodents and unknown species.

Diet diversity was higher in snow leopards than in wolves. Based on the number and biomass of individuals consumed, Levin's indices were 0.35 and 0.25 , respectively, for snow leopard; for wolf they were 0.31 and 0.17 . Pianka's index was 0.91 , indicating a large overlap in the diets of the two predators.

The crude densities of the two main prey species were estimated to be 0.67 and 1.79 individuals $\mathrm{km}^{-2}$ for ibex and argali, respectively. Observed and expected distributions of these prey species in the scats are shown in Table 1 . The observed frequencies of argali were as expected in both snow leopard and wolf. In wolf, ibex occurred less frequently than expected, whereas in snow leopard ibex occurred according to their availability in the Reserve.

\section{Discussion}

Three prey species, argali, Siberian ibex and marmot, accounted for $>90 \%$ of the food of both predators, with argali alone constituting $>50 \%$ of the diet for both. The narrow food base was not surprising, considering that livestock were unavailable and there are large differences in biomass between the two highly profitable ungulates and the smaller potential prey species. Although relatively abundant in the Reserve, hares, rodents and gallinaceous birds made up only a small proportion of the diets of the two carnivores. Except for studies in Nepal (Oli et al., 1993) and China (Schaller et al., 1988), our results agree well with what has been reported for snow leopards elsewhere (Anwar et al., 2011; Shehzad et al., 2012).

The low diversity and large overlap in diets, especially with respect to argali, suggest that the two carnivores may compete for food. Conversely, the primary prey species may be sufficiently abundant for both predators to exploit them without competitive interference. There is some evidence in support of the latter scenario: as smaller prey was readily available in the Reserve, the dominance of only two ungulate species and marmots in the diets indicates that the principal food resources (argali and ibex) were not critical for either snow leopards or wolves. This interpretation is supported by the relatively high crude density of 1.8 argali $\mathrm{km}^{-2}$ recorded during the autumn survey, which was probably an underestimate, according to a recent test of survey methods for this species (Wingard et al., 2011). Productivity was also relatively high, as evidenced by the composition of subsamples of observed herds $(n=33)$ : lambs constituted c. $18 \%$ of the autumn population, at a ratio of lambs to adult ewes of 0.52 , which is similar to the results from surveys conducted in the same general area a few years earlier (Klich \& Magomedov, 2010). A probable explanation for the lack of competition between the two carnivores in spite of similar and specialized diets is that the range quality for wild ungulates increased significantly following the termination of widespread and heavy grazing by livestock 13 years previously. This, combined with virtual cessation of hunting, could have facilitated an increase in the ungulate population. The population of wolves, which are persecuted when roaming outside the Reserve during winter, and the originally sparse population of snow leopards did not increase as quickly as that of their primary prey species (Reserve staff, pers. comm.). This scenario may allow wolves and snow leopards to share the same food resources without competition.

The alternative scenario is that competition is taking place, mainly because of food limitation among snow leopards. Ibex occupies the same rugged habitat as snow leopards and is a principal prey of this predator. In the Reserve the abundance of this prey may be limited relative to the numbers of snow leopards, leading the leopards to prey heavily on argali, thus competing with wolves for this resource. Although argali mainly occupy open ground away from ibex habitat (Schaller, 1976; Dzieciolowski et al., 1980; Namgail et al., 2004), small family groups of argali could be vulnerable to snow leopard attack when they graze within critical distances of snow leopard habitat during summer. As wolf packs rarely venture into the steep, rugged terrain of ibex when hunting (Viripaev \& Vorobiev, 1983), 
competition with snow leopard for this species occurs less frequently.

We collected carnivore scats in summer, when the prey base is more diverse than in winter. We found that marmots comprised a significant portion of the summer diets of both snow leopards and wolves, but especially of wolves. In winter, when marmots are unavailable because of hibernation, predation on the two ungulates would be expected to intensify, although wolves reportedly also obtain food by preying on domestic stock (mainly horses and sheep) outside the Reserve. Therefore, to further assess food competition and identify predator-prey interactions, the diets of the two carnivores also need to be monitored and compared during winter.

Ongoing trophy hunting outside the Reserve could potentially lead to population declines of ibex and argali. We would expect a reduction in the ibex population to have a direct negative effect on snow leopards, whereas the wolf is likely to be indirectly affected through more intense competition resulting from elevated predation on argali by snow leopards.

Our study area was more or less free of livestock grazing, making it atypical of the snow leopard's range, but the number of livestock is now increasing in the communities near the Reserve. This may pose a number of threats to ongoing conservation efforts, including escalation of human-carnivore conflicts, overgrazing and range deterioration, and transfer of disease to wild ungulate prey. It is therefore important that good management and protection of the Reserve be maintained in the coming years.

\section{Acknowledgements}

The study was funded by Panthera and the Snow Leopard Trust. The Sarychat-Ertash State Reserve provided logistical and personnel support for the fieldwork. We are grateful to Musaev Mukhtar (Director of the Sarychat-Ertash Reserve), Tomas McCarthy, Jennifer S. Rullmann and Raghunandan Singh Chundawat for assistance in various phases of the study. Laboratory facilities for the scat analysis were provided by the Norwegian University of Life Sciences.

\section{References}

Ackerman, B., Lindzey, F. \& Hemker, T. (1984) Cougar food habits in southern Utah. Journal of Wildlife Management, 48, $147-155$.

Anwar, M.B., Jackson, R.M., NAdeem, M.S., Janecka, J.E., Hussain, S., BeG, M.A. et al. (2011) Food habits of snow leopard Panthera uncia (Schreber, 1775) in Baltistan, northern Pakistan. European Journal of Wildlife Research, 57, 1077-1083.

Bagchi, S., Mishra, C. \& Bhatnagar, Y. (2004) Conflicts between traditional pastoralism and conservation of Himalayan ibex (Capra sibirica) in the Trans-Himalayan mountains. Animal Conservation, 7, 121-128.
Begon, M., Harper, J. \& Townsend, C. (1996) Ecology: Individuals, Populations and Communities. 2nd edition. Blackwell Science, Oxford, UK.

Brunner, H. \& Coman, B. (1974) The Identification of Mammalian Hair. Inkata Press, Melbourne, Australia.

BSAP (1996) Biodiversity Strategy and Action Plan, Kyrgyz Republic. Ministry of Environment and Protection, Bishkek, Kyrgyzstan.

Ciucci, P., Tosoni, E. \& Boitani, L. (2004) Assessment of the pointframe method to quantify wolf Canis lupus diet by scat analysis. Wildlife Biology, 10, 149-153.

Colwell, R.K. \& Futuyma, D.J. (1971) On the measurement of niche breadth and overlap. Ecology, 52, 567-576.

Dzieciolowski, R., Krupka, J., Bajandelger, K. \& Dziedzic, R. (1980) Argali and Siberian ibex populations in the Khuhsyr Reserve in Mongolian Altai. Acta Theriologica Sinica, 25, 213-219.

Floyd, T., Mech, L. \& Jordan, P. (1978) Relating wolf scat content to prey consumed. Journal of Wildlife Management, 42, 528-532.

Fox, J.L. (1994) Snow leopard conservation in the wild-a comprehensive perspective on a low-density and highly fragmented population. In Proceedings of the 7 th International Snow Leopard Symposium (eds J.L. Fox \& D. Jizeng), pp. 3-15. International Snow Leopard Trust, Seattle, Washington.

Harihar, A., Pandav, V. \& Goyal, S.P. (2011) Responses of leopard Panthera pardus to the recovery of a tiger Panthera tigris population. Journal of Applied Ecology, 48, 806-814.

Hines, J.E. \& Link, W.A. (1994) SCATMAN. USGS-Patuxent Wildlife Research Center, Maryland, USA.

Iyanushevich, A., Aizin, B., Kidiraliev, A., Umrihina, G., Fedianina, T. \& Shukurov, E. (1972) Mlekopitaiushie Kyrgizii [Mammals of Kyrgyzia]. Ilim, Frunze.

JACKson, R. \& Hunter, D. (1996) Snow Leopard Survey and Conservation Handbook. 2nd edition. International Snow Leopard Trust, Seattle, USA, and U.S. Geological Survey, Colorado, USA.

Janecka, J., Jackson, R., Yuquang, Z., Diqiang, L., Munkhtsog, B. \& Buckley-Beason, V. (2008) Population monitoring of snow leopards using noninvasive collection of scat samples: a pilot study. Animal Conservation, 11, 401-411.

Karanth, K. \& Sunquist, M. (2000) Behavioral correlates of predation by tiger (Panthera tigris), leopard (Panthera pardus), and dhole (Cuon alpinus) in Nagarahole, India. Journal of Zoology, 250, $255-265$.

Klich, D. \& Magomedov, R. (2010) Abundance, population structure and seasonally changing social organization of argali Ovis ammon karelini in West-Central Tien-Shan of Kyrgyzstan. Acta Theriologica, 55, 27-34.

Koshkarev, E.P. (1989) Снежный барс в Киргизии. Фрунзе: Илим. Koshikarev, E. \& Viripaev, V. (2000) Что случилось со снежным барсом после распада СССР? Охрана дикой природы, 19, 72.

Kyrgyz Hunting Agency (2010) Annual Report. Bishkek, Kyrgyzstan.

Lescureux, N. (2006) Towards the necessity of a new interactive approach integrating ethnology, ecology, and ethology in the study of the relationship between Kyrgyz stockbreeders and wolves. Social Science Information, 45, 463-478.

Link, W. \& KaRANTH, K. (1994) Correcting for overdispersion in tests of prey selectivity. Ecology, 75, 2456-2459.

Lovari, S., Boesi, R., Minder, I., Mucci, N., Randi, E., Dematteis, A. \& Ale, S. (2009) Restoring a keystone predator may endanger a prey species in a human-altered ecosystem: the return of the snow leopard to Sagarmatha National Park. Animal Conservation, 12, 559-570.

McCARthy, T.M. (2000) Ecology and conservation of snow leopards, Gobi bears and wild Bactrian camels in Mongolia. PhD thesis. University of Massachusetts, Amherst, USA. 
Mijiddorj, T. (2011) Pastoral practice and herders' attitude towards wildlife in south Gobi Mongolia. MS thesis. Saurashtra University, Rajkot, India.

Mishra, C. (1997) Livestock depredation by large carnivores in the Trans-Himalaya: conflict perceptions and conservation prospects. Environmental Conservation, 24, 338-343.

Múller, S. (2006) Diet Composition of Wolves (Canis lupus) on the Scandinavian Peninsula Determined by Scat Analysis. Technical University of Munich, Germany.

Namgail, T., Fox, J.L. \& Bhatnagar, Y.V. (2004) Habitat segregation between sympatric Tibetan argali Ovis ammon hodgsoni and blue sheep Psedois nayaur in the Indian Trans-Himalaya. Journal of Zoology, 262, 57-63.

Nowell, K. \& Jackson, R.M. (1996) Wild Cats: Status, Survey and Conservation Action Plan. IUCN, Gland, Switzerland.

Odden, M., Wegge, P. \& Eliassen, T. (2010) Do tigers displace leopards? If so, why? Ecological Research, 25, 875-881.

OLI, M.K. (1993) A key for the identification of the hair of mammals of a snow leopard (Panthera uncia) habitat in Nepal. Journal of Zoology, 231, 71-93.

Oli, M.K., Taylor, I.R. \& Rogers, M.E. (1993) Diet of the snow leopard (Panthera uncia) in the Annapurna Conservation Area, Nepal. Journal of Zoology, 231, 365-370.

Pianka, E. (1973) The structure of lizard communities. Annual Review of Ecology and Systematics, 4, 53-74.

Schaller, G.B. (1976) Mountain mammals in Pakistan. Oryx, 13, $351-356$.

Schaller, G.B., Junrang, R. \& Mingjiang, Q. (1988) Status of the snow leopard Panthera uncia in Qinghai and Gansu Provinces, China. Biological Conservation, 45, 179-194.

SER (2007) The Sarychat-Ertash State Reserve Management Plan 2007-2015. Bishkek, Kyrgyzstan.

Shehzad, W., McCarthy, T.M., Pompanon, F., Purevjav, L., Coissac, E., Riaz, T. \& Taberlet, P. (2012) Prey preference of snow leopard (Panthera uncia) in south Gobi, Mongolia. PLoS ONE, 7(2), e32104, doi: 10.1371.

Stewart, D.R.M. (1967) Analysis of plant epidermis in faeces: a technique for studying the food preferences of grazing herbivores. Journal of Applied Ecology, 4, 83-111.

Viripaev, V. \& Vorobiev, G. (1983) Волк в Киргизии. Фрунзе: Илим.
Weaver, J. (1993) Refining the equation for interpreting prey occurrence in gray wolf scats. Journal of Wildlife Management, $57,534-538$.

Wegge, P., Odden, M., Pokharel, C. \& Storaas, T. (2009) Predator-prey relationships and responses of ungulates and their predators to the establishment of protected areas: a case study of tigers, leopards and their prey in Bardia National Park. Biological Conservation, 142, 189-202.

Wegge, P., Shrestha, R. \& Flagstad, Ø. (2012) Snow leopard predation on livestock and wild prey in a mountain valley in northern Nepal: implications for conservation management. Wildlife Biology, 18, 131-141.

Weinberg, P.I., Fedosenko, A.K., Arabuli, A., Myslenkov, A., Romashin, A.V., Voloshina, I. \& Zheleznov, N. (1997) The commonwealth of independent states (former USSR). In Wild Sheep and Goats and their Relatives. Status Survey and Conservation Action Plan for Caprinae (ed. D.M. Shackleton), pp. 172-193. IUCN, Gland, Switzerland, and Cambridge, UK.

Wingard, G.J., Harris, R.B., Ambalanbaatar, S. \& READING, R. (2011) Estimating abundance of mountain ungulates incorporating imperfect detection: argali Ovis ammon in the Gobi Desert, Mongolia. Wildlife Biology, 17, 93-101.

ZLOTIN, R.I. (1997) Geographical organization of high mountain ecosystems in former USSR. In Ecosystems of the World 3. Polar and Alpine Tundra (ed. F.E. Wielgolaski), pp. 133-159. Elsevier Science, Amsterdam, The Netherlands.

\section{Biographical sketches}

KuBANYchBEK JUMABAy-UULU is now the coordinator of snow leopard conservation work in Kyrgyzstan, following a study of snow leopards and wolves in the Sarychat-Ertash Reserve. PER WEGGE's research interests include predator-prey relationships of large mammals, mainly in Nepal, and the impact of commercial forestry on boreal forest grouse. The research and conservation activities of Koustubh Sharma and Charudutt Mishra are centred on carnivores and wild and domestic ungulates in the Indian Himalayas, with a focus on mitigating predator-human conflicts. 